\title{
Genetic characterization of breeding systems, ploidy levels and species boundaries in Cypricercus (Ostracoda)
}

\author{
J. TURGEON \& P. D. N. HEBERT* \\ Department of Zoology, University of Guelph, Guelph, Ontario, Canada N1G 2W1
}

\begin{abstract}
Although freshwater ostracod crustaceans show an exceptionally high incidence of transitions from sexual reproduction to parthenogenesis, no prior studies have examined genetic relationships among congeneric species showing breeding system variation. The present study addresses this gap by examining patterns of allozyme diversity among three unisexual and three sexual species in the genus Cypricercus from 46 North American sites. Patterns of genetic relatedness among these taxa suggest that parthenogenesis has evolved on at least three occasions within the genus, and that one all-female taxon is closely related to a sexual species. One unisexual, $C$. reticulatus, showed very high clonal diversity with many polyploids as well as an allelic array suggesting that much of its diversity originated through interbreeding with sexual relatives. The other unisexuals showed both lower clonal and allelic diversity, but the prevalence of triploid clones suggested that variation might originate from hybridization between diploid asexuals and males of relict sexual populations. The prevalence of multiple X$\mathrm{Y}$ sex determination systems in the ostracods may explain the marked variation in chromosome numbers evident among polyploids. This study suggests that the success of unisexuals may be linked to their ability to recruit clonal diversity through interbreeding with close sexual relatives.
\end{abstract}

Kevwords: asexuality, clonal diversity, Ostracoda, parthenogenesis, polyploidy

\section{Introduction}

In an effort to gain a deeper understanding of the factors sustaining sexual reproduction, much effort has been directed towards the study of species assemblages which show breeding system variation (reviewed in Bell, 1982; Michod \& Levin, 1988). Researchers have compared the niche widths of sympatric sexual and asexual taxa (Vrijenhoek, 1984; Zhang \& Lefcort, 1992), gathered data on the association between habitat characteristics and breeding systems (Vandel, 1928; Suomalainen, 1969; Chaplin, 1991), and compared the parasite loads of sexual and asexual taxa (Moritz et al., 1991; Ladle, 1993). Genetic studies have provided insights concerning both the fate of asexuals and the origins of their genetic diversity (Dawley \& Bogart, 1989; Hebert et al., 1989). This work has shown that many asexuals gain genetic diversity through matings with close sexual relatives (Lynch, 1984), a result which has

\footnotetext{
*Correspondence.
}

provoked a terminological shift to recognize properly the nuances of variation in breeding systems. Unisexual taxa include only females, but these individuals engage, at least occasionally, in quasi-sexual processes to generate diversity, while true asexuals have abandoned such contact. As genetic studies have progressed, it has become clear that most putative asexuals are in fact unisexuals employing occasional sexual reproduction. It is now also evident that genotypically diverse unisexuals are not doomed to a brief persistence (Maynard Smith, 1986; Hedges et al., 1992) and that they employ a variety of processes to generate diversity. Many unisexual animals are derived from the hybridization of different sexual species, and repeated hybridization events can augment their diversity (Dawley \& Bogart, 1989). Other unisexuals, which lack a hybrid origin, mate occasionally with close sexual relatives generating new polyploid derivatives (e.g. Turgeon \& Hebert, 1994). Still other unisexuals rely on rare episodes of male production and sexual recruitment to increase their genotypic diversity (Pernin et al., 1992). 
Past studies have revealed a paradox - unisexuals are successful in space, but not in time (Williams, 1975; Maynard Smith, 1978; Bell, 1982). Thus, many extant unisexuals are common and have broad geographical distributions, yet the fossil record indicates that their success is generally ephemeral. The resolution of this paradox may lie in gaining a better understanding of interactions between sexuals and unisexuals. If, for example, the recruitment of diversity from sexual relatives is critical to their success, then unisexuals might show a 'life-cycle'. The low level of clonal diversity in newly emergent unisexuals would be rapidly augmented by clones generated through interbreeding with sexual ancestors. These clones might in turn displace the sexuals, and, in so doing, terminate the primary diversity-generating mechanism and set the stage for extinction of the taxon.

Further study is required to extend understanding of the nature and impacts of interactions in unisexual-sexual assemblages. Because of their broad distribution and the existence of closely related unisexual and mixed-sex taxa, the ostracod crustaceans offer an unrivalled opportunity for such work (Bell, 1982). This study exploits this fact and examines patterns of genetic diversity in the ostracod genus Cypricercus ( = Bradleystrandesia, Meisch et al., 1990). Twelve of the 16 North American species in this genus reproduce sexually (Tressler, 1959), but there are also four unisexual species which are common and broadly distributed. Previous genetic information on Cypricercus is restricted to a survey of two of these unisexuals at a site in the Canadian arctic (Havel et al., 1990), where one species, C. reticulatus Zaddach, displayed a very high level of clonal diversity, while the other taxon, $C$. horridus Sars, showed little clonal variation. The taxonomy of North American members of Cypricercus is confused - extensive morphological variation complicates the designation of species boundaries (Furtos, 1933; Hoff, 1942; Tressler, 1959; Delorme, 1970) and variation in breeding system occurs among apparently conspecific populations. In $C$. reticulatus, for example, males are known, but the large majority of populations contain only females (Hoff, 1942). Past breeding system determinations have relied on gender ratio analyses, with parthenogenesis being inferred for all-female populations. Genetic studies have now established the general validity of breeding system assignments made using the approach (Havel \& Hebert, 1989), as the presence of males, even at low frequency, has always been associated with sexual recruitment (Chaplin, 1993).

Prior to investigating the evolutionary interactions between sexual and unisexual members of Cypricercus, it was critical that both species boundaries and breeding systems of individual taxa be accurately defined. In this paper, allozyme markers are used to ascertain the degree of genetic differentiation among the six taxa of Cypricercus detected in ponds from the lower Laurentian Great Lakes area. The breeding system of each taxon is also assessed by examining the genetic structure of populations, and the incidence of polyploids ascertained through both allozyme and cytogenetic studies.

\section{Materials and methods}

\section{Collections and identification}

Ostracods were collected from 46 ponds in southern Ontario, Pennsylvania and Ohio (Fig. 1). Specimens were initially examined in 1991 to identify levels of morphological and allozymic polymorphism, but the data in this paper largely result from single collections made in the spring of 1992 . However, five habitats were sampled on several occasions in either the spring or in both the autumn and spring. Spring sampling ceased by the end of May, as Cypricercus species are typically univoltine and produce resting eggs in early summer which diapause until late fall or early winter.

Ostracods in the samples were identified to the generic level and all members of the genus Cypricercus were retained for study. Approximately 50 animals of each morphological type present in a particular habitat were immediately frozen in liquid nitrogen for later allozyme analysis. Adults were separated by morphology into six taxa in accordance with Hoff (1942), Furtos (1933) and Delorme (1970). Specimens of four taxa corresponded closely to the descriptions for Cypricercus splendida Furtos, $C$. fuscatus Jurine, C. tincta Furtos and $C$. horridus. Other individuals were identified as $C$. deltoidea Delorme, but they were slightly more elongate than is typical of this species. All remaining individuals were assigned to $C$. reticulatus. These were all females showing similarity in their shell shape and surface texture, but much variation in coloration and banding pattern.

Two sexual species ( $C$. splendida, $C$. deltoidea) and one unisexual taxon ( $C$. horridus) showed little morphological variation, but the other three species were more variable. Differences in muscle scar patterns permitted the separation of one of these taxa (C. reticulatus) from the other two ( $C$. fuscatus, $C$. tincta). In $C$. fuscatus, four morphs with differing carapace coloration (brown, green, red, yellow) were 
Fig. 1 Distributions of six species of Cypricercus among 46 sampling sites in North America. Sites 1-44 = ONT.

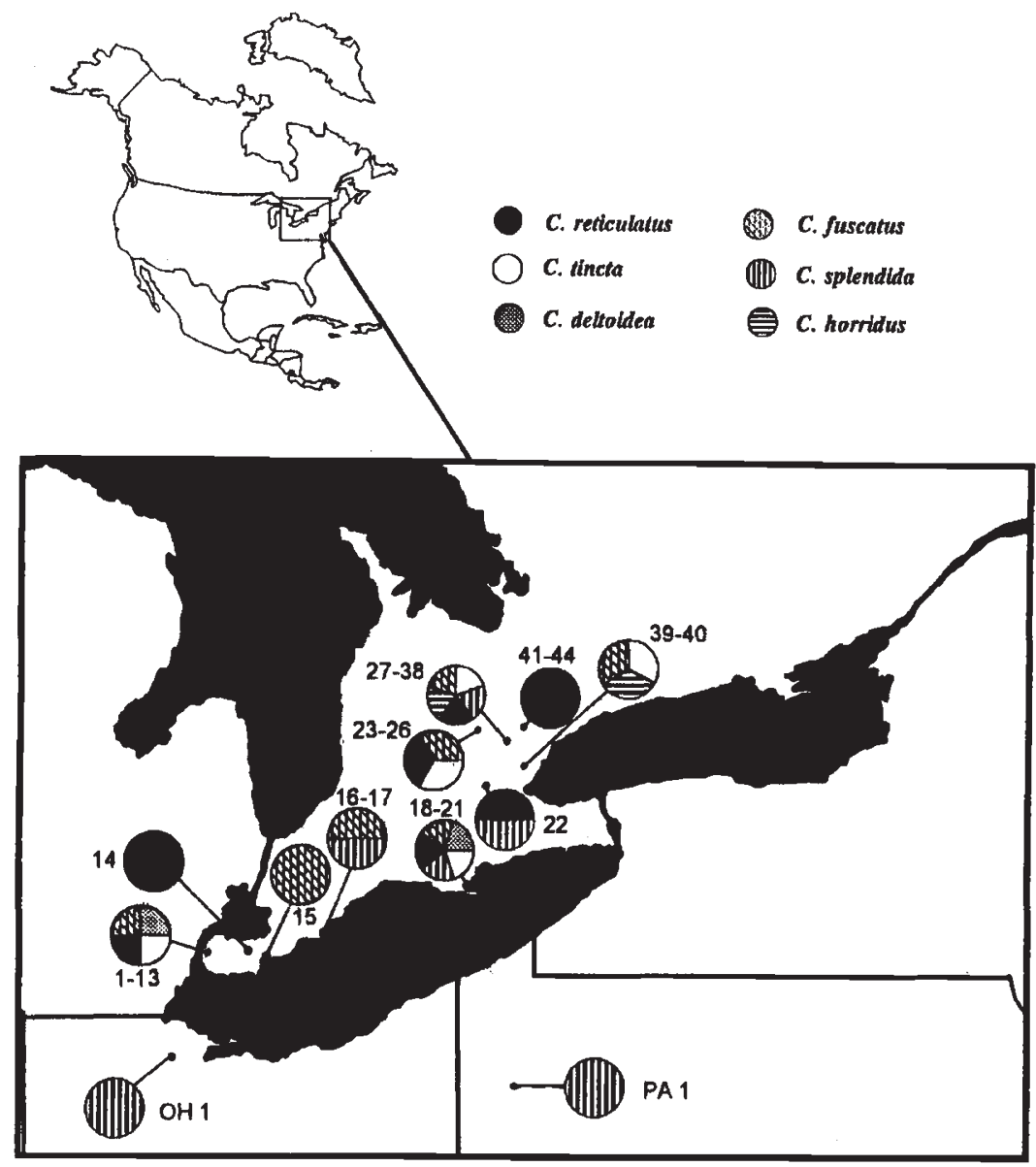

observed and individuals of the brown morph were very similar to females of $C$. tincta. Each species in a pond was examined for the presence of males and individuals for the two all-female taxa, which showed marked colour variation, were assigned to a particular morph.

\section{Electrophoresis}

Cellulose acetate enzyme electrophoresis was performed following standard methods (Hebert \& Beaton, 1993). During 1991, approximately 50 individuals from each of 22 ponds were screened for variation at nine enzyme systems: aspartate aminotransferase (Aat, EC 2.6.1.1), arginine phosphokinase (Apk, EC 2.7.3.3), fumarate hydratase (Fumh, EC 4.2.1.2), glucose-6-phosphate isomerase (Gpi, EC 5.3.1.9), isocitrate dehydrogenase (Idh, EC 1.1.1.42), malate dehydrogenase (Mdh, EC 1.1.1.37), mannose-6-phosphate isomerase ( $M p i$, EC 5.3.1.8), peptidase (Pep, EC 3.4.11, substrate: leucyl-glycine) and phosphoglucomutase (Pgm, EC 5.4.2.2). These analyses showed a lack of variation at $M d h$, but revealed variation at 10 loci in the other eight enzyme systems. In 1992, about 50 individuals of each species from each pond were scored for variation at these 10 loci. At each locus, electromorphs with increasing anodal mobility were assigned ascending letter codes.

\section{Data analysis}

Individuals were assigned to a specific taxon and allozyme data collected as multilocus genotypes. Each species from a given pond, with electrophoretic data on 20 or more individuals, represented a population for data analysis using BIOSYS-1 (Swofford \& Selander, 1989). Among those taxa employing sexual reproduction, heterozygote banding patterns were consistent with those expected based on the quaternary structure of the enzyme (Hebert \& Beaton, 1993). However, unusual allozyme patterns containing extra bands or unbalanced staining activities were noted in individuals of each unisexual taxon. For example, heterozygous phenotypes at the monomeric Pgm locus were occasionally three-banded in $C$. reticulatus and $C$. fuscatus, whereas some individuals of $C$. reticulatus showed five or six bands 
at the dimeric Gpi locus. Only the slowest and fastest bands of these patterns were considered in assigning a diallelic genotype for data entry in BIOsys- 1 . The rationale behind this procedure is that these bands probably represent the slowest and fastest homodimers being expressed, whereas the origin of the intermediate bands cannot be unambiguously determined. Unless indicated otherwise, samples taken on different dates were treated as different populations, and taxa were never partitioned, with the exception of one sample of $C$. fuscatus (ONT7. spring), which was subdivided in two groups (see Results section). A cophenetic matrix of Rogers's genetic distances (Rogers, 1972) was used to produce a UPGMA dendrogram in BIOSYS- 1 and to carry out a multidimensional scaling (MDS) procedure in SYSTAT (Wilkinson, 1990). The algorithm used in SYSTAT treats the genetic distances in the matrix as ordinal data, helping to prevent intergroup differences from concealing intragroup variability.

The breeding system of each population was assigned by examining gender ratios and by testing the conformance of genotypic frequencies to HardyWeinberg expectations, using exact probabilities. The probabilities were subjected to a sequential Bonferroni procedure, to determine table-wide significance levels. Where genotypic frequencies deviated significantly from expectations at several polymorphic loci, or when males were absent, the genotypic structure of the population was further characterized using three parameters: (1) the number of unique 10-locus genotypes, (2) a log-transformed mean probability of the observed genotypic arrays conforming to Hardy-Weinberg expectations, and (3) a genotypic diversity ratio (GDR, observed/ expected). The rationale and method for calculation of these parameters are discussed in Hebert et al., (1988).

Species diversity in Cypricercus was examined using a combinatorial approach (Hebert et al., 1989) which examined the relationship between the number of species detected and the number of ponds analysed.

\section{Cytogenetic studies}

Chromosome counts on ovarian tissue from mature females were made to determine if there was karyotypic variation among the sexual species, and also to verify the occurence of polyploidy in clones of the unisexual taxa. Cytogenetic techniques were modified from Tetart $(1969,1978)$ and are detailed in Turgeon (1993).

\section{Results}

\section{Morphological and allozymic recognition of Cypricercus taxa}

Three of the six taxa appeared to reproduce sexually, as their populations regularly included individuals of both genders, while the other taxa consisted, with one possible exception, solely of females. Half of the ponds (23 of 46) contained more than one species of Cypricercus, with an average of 1.79 taxa per pond. A plot of the number of clones detected as a function of the number of ponds sampled showed an asymptotic relationship, suggesting that all of the species present in the sampling area were encountered.

Separation of $C$. reticulatus from the other species using allozyme characters was sometimes ambiguous, as it was very genetically diverse, possessing the complete spectrum of alleles detected in the other species (Table 1). Individuals of this species did possess some unique alleles (Fumh b, Aat d, Idh$1 \mathrm{~b}$ ), but they were ordinarily in heterozygous condition. However, the Pep-2 c allele, which was predominant in $C$. reticulatus but absent from all other species excepting a few clones of $C$. fuscatus, was most useful for its recognition. The remaining taxa were more distinctive. Individuals of $C$. splendida were generally distinguished from other species by their possession of a unique fast allele (e) at $I d h$ 1. C. deltoidea was fixed at Pep-2 and Idh-1 for alleles shared only with $C$. horridus, but was differentiated from this taxon at $A p k$. C. horridus was itself differentiated from the other taxa by a unique allele at Pgm. C. tincta and $C$. fuscatus were closely related, sharing alleles at all but $I d h-2$.

Both the UPGMA dendrogram (Fig. 2) and multidimensional scaling (Fig. 3) confirmed the presence of six major genetic groups. As might have been expected from their morphological distinctiveness, $C$. deltoidea, $C$. splendida and $C$. horridus populations were well discriminated genetically, while populations of $C$. fuscatus and $C$. tincta were very similar. Populations of $C$. reticulatus showed the highest level of intraspecific genetic divergence.

\section{Breeding systems}

Males were invariably present in populations of $C$. splendida, $C$. deltoidea and $C$. tincta. Populations of these three species were commonly polymorphic at $G p i$ and $I d h-1$, and genotypic frequencies at these loci invariably conformed to Hardy-Weinberg expectations. Rare polymorphisms were also detected at three other autosomal loci (Aat and Pep-1

(c) The Genetical Society of Great Britain, Heredity, 75, 561-570. 
Table 1 Allelic arrays and pooled allelic frequencies at 10 loci for six species of Cypricercus. $+0^{*}=$ sexual taxon; $q=$ unisexual taxon

\begin{tabular}{|c|c|c|c|c|c|c|c|}
\hline Locus & $\begin{array}{c}\bar{N} \\
\text { Allele }\end{array}$ & $\begin{array}{c}238 \\
\text { C. deltoidea }\end{array}$ & $\begin{array}{l}477 \\
\text { C. splendida }\end{array}$ & $\begin{array}{c}413 \\
\text { C. tincta }\end{array}$ & $\begin{array}{l}503 \\
\text { C. fuscatus }\end{array}$ & $\begin{array}{c}1330 \\
\text { C. reticulatus }\end{array}$ & $\stackrel{50}{\text { C. horridus }}$ \\
\hline & & †ै & †े & $q \hat{0}$ & $q$ & q & q \\
\hline \multirow[t]{6}{*}{$G p i$} & $a$ & - & - & - & 0.005 & - & 0.5 \\
\hline & b & - & - & 0.136 & 0.675 & 0.032 & 0.5 \\
\hline & c & - & - & 0.863 & 0.036 & 0.075 & - \\
\hline & d & 0.020 & 0.553 & - & 0.284 & 0.524 & - \\
\hline & $\mathrm{g}$ & 0.911 & 0.332 & - & - & 0.249 & - \\
\hline & $\mathrm{h}$ & 0.069 & 0.115 & - & - & 0.120 & - \\
\hline \multirow[t]{7}{*}{$P g m$} & a & - & 0.679 & 0.288 & 0.082 & 0.014 & - \\
\hline & $\mathrm{b}$ & 0.002 & 0.207 & 0.374 & 0.080 & 0.005 & - \\
\hline & c & 0.679 & 0.029 & 0.006 & 0.338 & 0.607 & - \\
\hline & $\mathrm{e}$ & - & 0.085 & 0.322 & 0.501 & 0.011 & - \\
\hline & f & 0.297 & - & - & - & 0.314 & - \\
\hline & $\mathrm{g}$ & 0.022 & - & - & - & 0.048 & 0.730 \\
\hline & $\mathrm{h}$ & - & - & - & - & - & 0.270 \\
\hline \multirow[t]{8}{*}{$M p i$} & a & - & 0.037 & - & 0.060 & - & - \\
\hline & b & - & 0.641 & - & - & 0.005 & 0.500 \\
\hline & c & - & 0.322 & 0.166 & 0.936 & 0.014 & - \\
\hline & $\mathrm{d}$ & - & - & 0.834 & 0.004 & 0.181 & 0.230 \\
\hline & $\mathrm{e}$ & - & - & - & - & 0.278 & 0.270 \\
\hline & $\mathrm{f}$ & 0.528 & - & - & - & 0.518 & - \\
\hline & h & 0.472 & - & - & - & 0.005 & - \\
\hline & $\mathrm{a}$ & - & - & - & - & 0.001 & - \\
\hline \multirow[t]{2}{*}{$A p k$} & b & - & 1.0 & 1.0 & 1.0 & 0.774 & 1.0 \\
\hline & $\mathrm{c}$ & 1.0 & - & - & - & 0.225 & - \\
\hline \multirow[t]{4}{*}{ Fumh } & b & - & - & - & - & 0.044 & - \\
\hline & c & - & - & 0.007 & - & 0.235 & 1.0 \\
\hline & d & 1.0 & 1.0 & 0.160 & - & 0.659 & - \\
\hline & $\mathrm{e}$ & - & - & 0.833 & 1.0 & 0.061 & - \\
\hline \multirow[t]{4}{*}{ Aat } & b & - & 1.0 & 1.0 & 0.997 & 0.096 & - \\
\hline & c & 0.993 & - & - & 0.002 & 0.022 & 1.0 \\
\hline & d & - & - & - & - & 0.793 & - \\
\hline & e & 0.007 & - & - & 0.001 & 0.088 & - \\
\hline \multirow[t]{4}{*}{ Pep-1 } & b & - & 1.0 & - & 0.008 & 0.092 & - \\
\hline & c & - & - & 1.0 & 0.361 & 0.297 & 0.270 \\
\hline & $d$ & 0.993 & - & - & 0.212 & 0.545 & 0.730 \\
\hline & $\mathrm{e}$ & 0.007 & - & - & 0.419 & 0.065 & - \\
\hline \multirow[t]{3}{*}{ Pep-2 } & b & 1.0 & - & - & - & - & 1.0 \\
\hline & c & - & - & - & 0.079 & 0.984 & - \\
\hline & d & - & 1.0 & 1.0 & 0.921 & 0.016 & - \\
\hline \multirow[t]{6}{*}{$I d h-1$} & $\mathrm{a}$ & - & 0.235 & - & - & 0.002 & - \\
\hline & b & - & - & - & - & 0.002 & - \\
\hline & c & - & - & 1.0 & 1.0 & 0.995 & - \\
\hline & d & 1.0 & - & - & - & - & 1.0 \\
\hline & $\mathrm{e}$ & - & 0.764 & - & - & - & - \\
\hline & f & - & 0.001 & - & - & - & - \\
\hline \multirow[t]{3}{*}{$I d h-2$} & a & - & 1.0 & - & - & 0.796 & 1.0 \\
\hline & b & 1.0 & - & 1.0 & 0.007 & 0.010 & - \\
\hline & $c$ & - & - & - & 0.993 & 0.194 & - \\
\hline
\end{tabular}




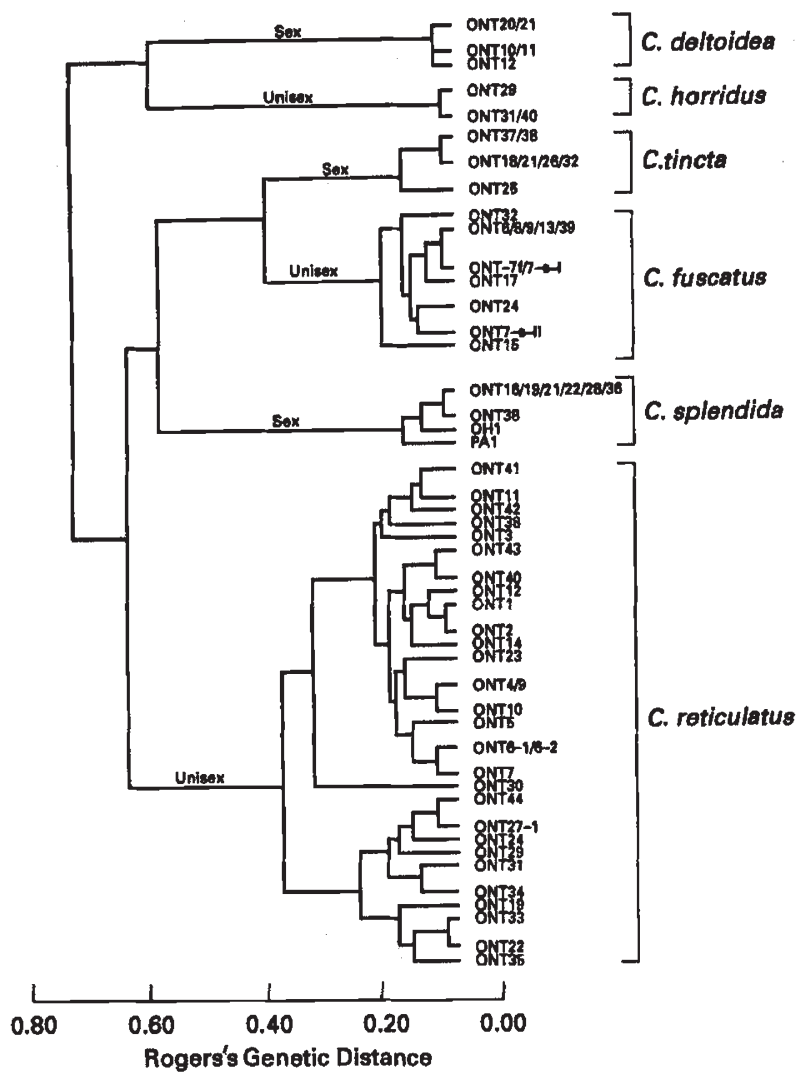

Fig. 2 UPGMA dendrogram of Rogers's genetic distances among samples from 65 Cypricercus populations $(N=2$ for $C$. horridus at ONT31 and ONT40). Branch nodes located at distances less than 0.1 are not shown. Populations are coded as in Fig. 1.

in C. deltoidea, Fumh in C. tincta) and again HardyWeinberg expectations were approximated. All three taxa were also polymorphic at Pgm and $\mathrm{Mpi}$, loci which were sex-linked. Significant deviations from Hardy-Weinberg expectations at these loci were uncommon in females of $C$. tincta and $C$. deltoidea, but more frequent in $C$. splendida. In all cases, these deviations were a result of heterozygote deficits. As expected, most males showed allozyme phenotypes compatible with hemizygosity, but a few heterozygotes were observed.

In all but one population of the other three species ( $C$. fuscatus, $C$. horridus, $C$. reticulatus) males were absent and their genetic structure was strikingly different from that of the sexual taxa. Their genotypic diversity was much lower than what would have been expected under sexual recruitment, and allozyme phenotypes suggestive of polyploidy were commonly observed.

With the exception of a spring sample from ONT7, all populations of $C$. fuscatus contained few clones, had a low GDR, and showed marked Hardy-

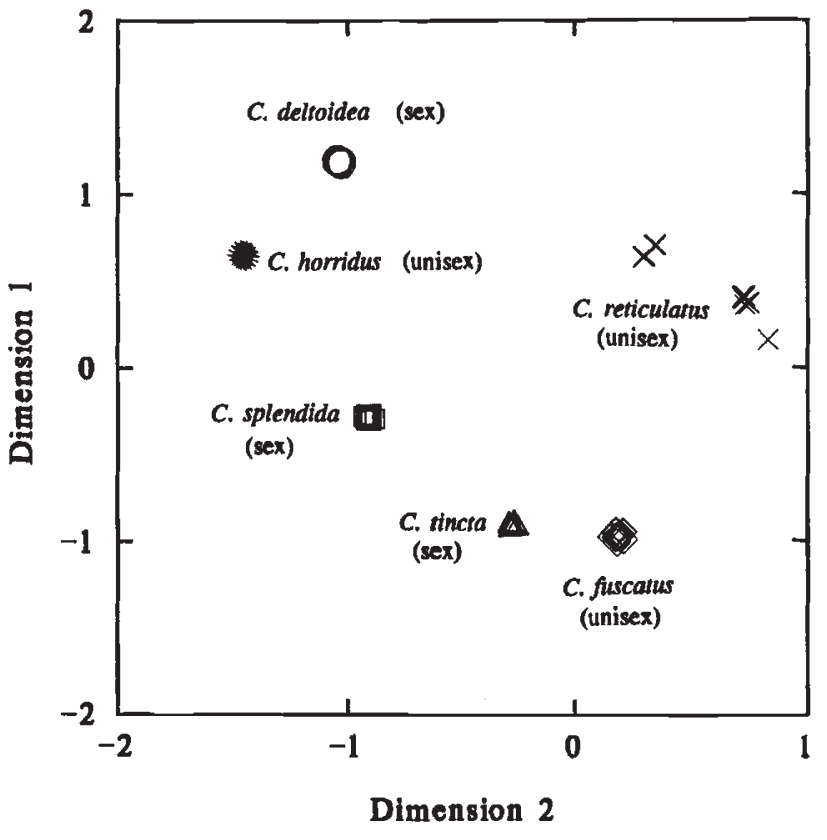

Fig. 3 Plot of Euclidean scores, as obtained by multidimensional scaling of Rogers's genetic distance among 65 North American populations of Cypricercus.

Weinberg deviations (Fig. 4a). Only 11 clones were detected in the 10 ponds with this species, and allozyme phenotypes suggested that nine of these clones were polyploid (Table 2). More specifically, staining activity was unbalanced at $G p i$ in six clones $(1,2,7$, and 9-11) and at Pgm and $\mathrm{Mpi}$ in one clone (4); in addition three-banded patterns were present at the monomeric Pgm locus in three clones (3,5 and 7). Temporal studies of clonal composition of $C$. fuscatus at ONT24 revealed the same clone on each of four sampling dates. By contrast, the extent of genotypic diversity in $C$. fuscatus from ONT7 showed a seasonal shift. The genotypic structure of the fall sample was typical of other populations, with only two clones being detected, but 18 genotypes were detected in the spring sample. Among these individuals, three genotypes appeared polyploid, displaying unbalanced staining activities at Gpi. These observations suggest that the $C$. fuscatus in the spring sample could be split into two groups - a low diversity assemblage including 27 females assignable to four different genotypes, and a high diversity assemblage containing 19 females and 2 males with 14 different genotypes. When the three parameters used to characterize genotypic composition were calculated separately for these groups, group I showed affinity with all other populations of $C$. fuscatus, while group II possessed the genotypic characteristics typical of sexual reproduction (Fig. 4a).

Only two multilocus genotypes, both heterozygous 

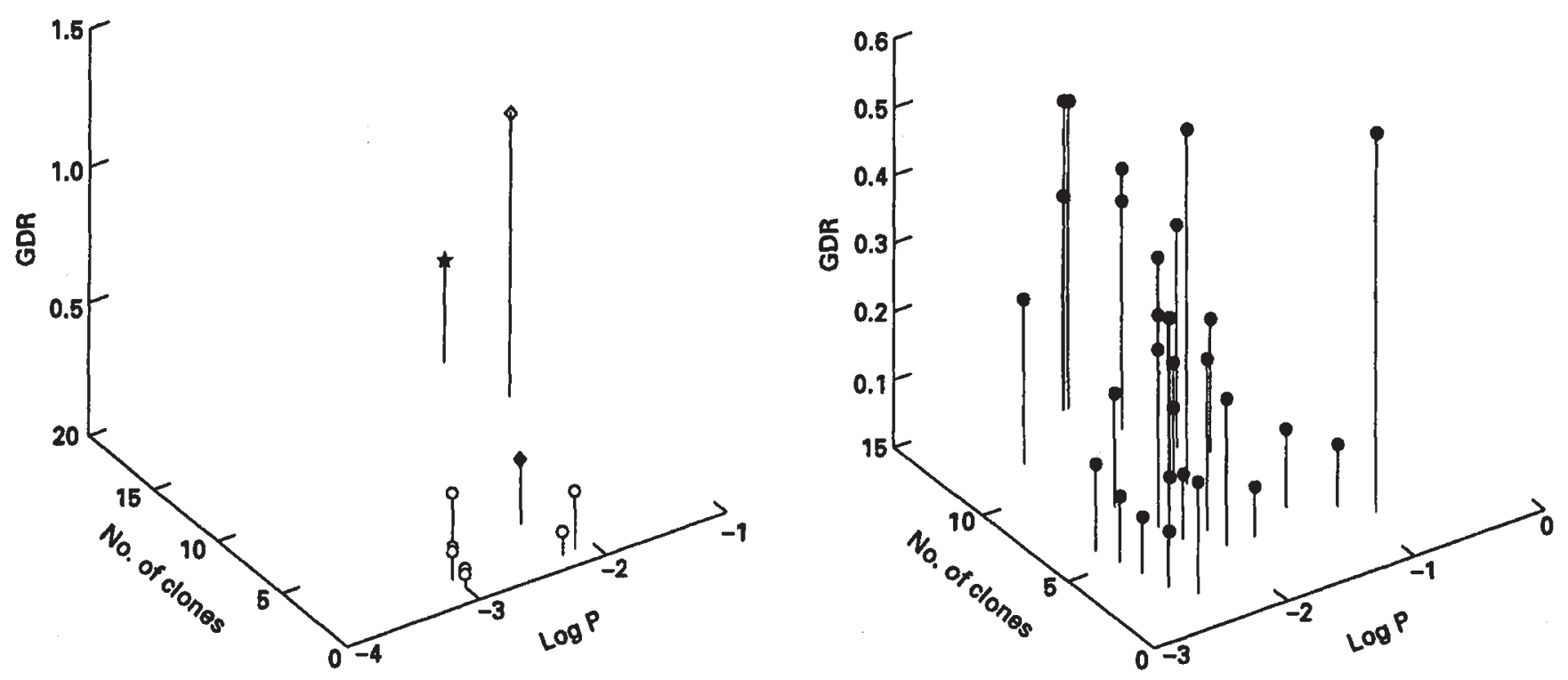

Fig. 4 Number of clones, $\log$ mean probability of observed genotypic frequencies (log $P$ ), and genotypic diversity ratios (GDR) for: (a) 12 samples of Cypricercus fuscatus, where $\star=$ sample from ONT7 (spring) which is divided into two subpopulations (see Results), $\square=$ sub-population I, $\square=$ sub-population II; and for (b) 31 samples of $C$. reticulatus.

Table 2 Multilocus genotypes at five polymorphic loci for 11 clones of Cypricercus fuscatus found in Ontario

\begin{tabular}{|c|c|c|c|c|c|c|c|c|}
\hline Clone & Colour & Gpi & $P g m$ & Mpi & Pep-1 & Pep-2 & Individuals & Habitats \\
\hline 1 & Green & $b^{*} d$ & $\mathrm{ce}$ & $c c$ & $\mathrm{ce}$ & dd & 244 & 6 \\
\hline 2 & Brown & $b^{*} d$ & $\mathrm{ce}$ & cc & $\mathrm{dd}$ & dd & 6 & 1 \\
\hline 3 & Green & $\mathrm{bb}$ & ace & $\mathrm{cc}$ & de & $\mathrm{dd}$ & 120 & 1 \\
\hline 4 & Red & $\mathrm{bb}$ & be* & $a^{*} c$ & $\mathrm{ce}$ & $\mathrm{dd}$ & 60 & 1 \\
\hline 5 & Green & $\mathrm{bb}$ & bce & $\mathrm{cc}$ & dd & $\mathrm{cd}$ & 4 & 1 \\
\hline 6 & Green & $\mathrm{bb}$ & $\mathrm{ce}$ & cc & $\mathrm{ce}$ & $\mathrm{cd}$ & 48 & 1 \\
\hline 7 & Green & $b^{*} c$ & ace & $\mathrm{cc}$ & dd & $\mathrm{cd}$ & 25 & 1 \\
\hline 8 & Brown & $\mathrm{bb}$ & be & cc & dd & dd & 6 & 1 \\
\hline 9 & Brown & $b^{*} d$ & ce & $\mathrm{cc}$ & dd & dd & 30 & 1 \\
\hline 10 & Yellow & $a b^{*}$ & ae & cc & dd & dd & 5 & 1 \\
\hline 11 & Brown & $b^{*} c$ & ce & $\mathrm{cc}$ & dd & dd & 7 & 1 \\
\hline
\end{tabular}

Carapace colouration for each clone is indicated.

*Indicates that the staining intensity of an allele was stronger than expected, suggesting polyploidy.

at several loci, were present in the sole population of $C$. horridus (ONT29) with an adequate sample size for analysis. Both clones appeared to be polyploid, providing further support for concluding that this species reproduced asexually (Table 3 ). Clone 1 was also identified in small samples from two other sites (ONT31 and ONT40).

Cypricercus reticulatus populations also appeared to reproduce asexually. A total of 185 clones was detected among 1364 individuals, and although as many as 14 clones were detected in a single population, the genotypic diversity was always less than 56 per cent of that expected under sexual reproduction
(Fig. 4b). The complete absence of males and the significant deviations of genotypic frequencies from Hardy-Weinberg expectations at most polymorphic loci (67 per cent) were also indicative of parthenogenetic reproduction. Moreover, allozymic and cytogenetic studies confirmed that many of these clones were polyploid.

\section{Chromosome numbers in Cypricercus}

Cytogenetic studies indicated that females of the three sexual species each possessed 22 chromosomes (Table 4). In C. deltoidea and C. tincta, meiotic pair- 
ing was observed, revealing haploid complements of 11 chromosomes. Chromosome counts were much more variable in the unisexual species, and meiotic figures were never observed. Clones of $C$. horridus and $C$. fuscatus, showing allozyme phenotypes suggestive of polyploidy, possessed chromosome numbers which were elevated above the usual diploid level, although not a simple multiple of it (Table 4). Females of $C$. reticulatus showed variation in chromosome number that was linked to carapace coloration. Individuals of the striped brown morph from two habitats showed a chromosome count suggestive of diploidy, while both clones with a green colouration appeared polyploid.

\section{Discussion}

This study has involved a genetic analysis of the six Cypricercus species which dominate ponds in the middle of the North American continent. Sex ratio determinations and genetic analysis confirm that three of these species are sexual and three are parthenogens. Morphological discrimination of these species is ordinarily possible, but the present study has also identified diagnostic allozyme markers that permit verification of species determinations.

The three sexual species included in this study show close similarity in their genetic structure. The

Table 3 Multilocus genotypes at four polymorphic loci for the two clones of Cypricercus horridus detected in Ontario

\begin{tabular}{lccccc}
\hline Clone & $G p i$ & $P g m$ & $M p i$ & Pep-1 & $N$ \\
\hline 1 & $\mathrm{a} * \mathrm{~b}$ & gg & bd & dd & $21,2,2$ \\
2 & $\mathrm{a}$ b & gh & bde & de & 28 \\
\hline
\end{tabular}

*Indicates that the staining intensity of an allele was stronger than expected, suggesting polyploidy.

$N$ : Number of indiyiduals in ONT29, ONT31 and ONT40, respectively. same two loci (Pgm and $\mathrm{Mpi}$ ) were sex-linked in all three taxa, while five other loci (Gpi, Idh-1, Fumh, Aat, Pep-1) appeared autosomal with genotypic frequencies consistent with Hardy-Weinberg expectations. The sex-linked loci showed both occasional heterozygote deficits in females and the occurrence of rare heterozygous males, results that suggest the prevalence of nondisjunction events.

The three species whose populations contained only females shared several genetic attributes. Genotypic frequencies at polymorphic loci in all three species showed large Hardy-Weinberg deviations, and individual populations contained many fewer multilocus genotypes than expected in a sexually reproducing taxon. As well, all three taxa were clonally diverse, although the extent of genetic diversity varied among species. Only two clones were detected for the rarest species ( $C$. horridus), compared with 11 clones for the species of intermediate abundance ( $C$. fuscatus), and 185 clones for the most common species, C. reticulatus (Turgeon, 1993). Allozyme phenotypes suggested that polyploidy was common in each species, with both clones of $C$. horridus showing signs of polyploidy, 82 per cent of the clones of $C$. fuscatus ( 90 per cent of individuals) and 44 per cent of those of $C$. reticulatus (50 per cent of individuals; Turgeon, 1993).

Tetart (1978) has shown that ostracods of the family Cyprididae (including Cypricercus) have a haploid complement ranging from 10-12. The present study confirms this result, establishing that females of the three sexual Cypricercus species have a haploid complement of 11 . In his extensive cytogenetic studies on ostracods from France, Tetart (1978) recognized triploidy in only one taxon, Eucypris virens. In this case, the evidence was clear three cytotypes had 23 or 24 chromosomes, while three others had chromosome numbers ranging from 32 to 37. Although Tetart (1978) noted that the chromosomes of several other unisexual species

Table 4 Chromosome counts for six Cypricercus species

\begin{tabular}{|c|c|c|c|c|c|}
\hline Species & Morph & Pond & No. of individuals & No. of spreads & No. of chromosomes \\
\hline C. deltoidea & - & ONT11 & 2 & 14 & 22 \\
\hline C. splendida & - & ONT16 & 2 & 20 & 22 \\
\hline C. tincta & - & ONT23 & 2 & 4 & 22 \\
\hline C. fuscatus & Red (clone 4) & ONT32 & 1 & 6 & 28 \\
\hline C. horridus & - & ONT29 & 1 & 6 & $28-31$ \\
\hline \multirow[t]{4}{*}{ C. reticulatus } & Striped-brown & ONT6 & 1 & 1 & 23 \\
\hline & Striped-brown & ONT14 & 2 & 10 & $20-23$ \\
\hline & Striped-green & ONT6 & 1 & 6 & $32-37$ \\
\hline & Plain-green & ONT14 & 1 & 3 & $28-34$ \\
\hline
\end{tabular}


could not be arranged into homologous pairs and that their chromosome numbers were elevated, he failed to categorize them as polyploids. For example, he assigned a diploid status to all Cypricercus, although individuals of one species $(C$. affinis $=C$. reticulatus) had 33 chromosomes, while among the eight cytotypes of $C$. fuscatus, two contained as many as 27 chromosomes. In retrospect, it seems probable that many of these cases represent polyploids. The failure of chromosome numbers to vary as a simple multiple of the basic haploid count is probably a consequence of the prevalence of multiple X$\mathrm{Y}$ sex determination systems in ostracods. For example, females of Cyprinotus incongruens (Bauer, 1940; Dietz, 1958) have a chromosome count of 20 $(8 \mathrm{~A}, 12 \mathrm{X})$ while males possess just $15(8 \mathrm{~A}, 6 \mathrm{X}, 1 \mathrm{Y})$. Males of this species produce sperm containing either 5 or 10 chromosomes, setting the stage for the production of triploids with either 25 or 30 chromosomes. The present study revealed polyploids in both $C$. horridus and $C$. fuscatus with relatively low chromosome counts, suggesting that their origin was a result of the fusion of a male determining sperm and diploid eggs. By contrast, the polyploid clones in $C$. reticulatus had higher chromosome numbers, compatible with their origin from the fusion of female determining sperm and a diploid egg.

The present study has identified one pair of taxa which may be particularly useful in studying the transition from sexual to asexual reproduction. These taxa ( $C$. fuscatus, $C$. tincta) possess differing breeding systems, but are allozymically and morphologically very similar. At 3 of the 46 sites, females of these two taxa co-occurred and were both genetically and morphologically distinctive. The situation at ONT7 was more complex. This population was initially classified as $C$. fuscatus because an autumn sample contained only two different clones. However, genotypic diversity was far higher in a spring sample, and males were detected. The surge in clonal diversity might be linked to the sympatric occurrence of $C$. tincta, but this seemed unlikely as most spring individuals possessed the diagnostic $C$. fuscatus allele at $I d h-2$. Alternatively, these individuals may represent a rare sexual population of $C$. fuscatus. Variation in reproductive mode has been reported for other species of freshwater ostracods on the basis that males were present in some populations, but absent from others (Bell, 1982). More recently Chaplin (1992) provided genetic evidence that both sexual and asexual individuals were present in each of two morphs of Candonocypris novaezelandiae, and also found that the co-occur- rence of forms with differing breeding systems was rare.

Some conclusions regarding the nature and frequency of breeding system transitions in the genus Cypricercus can be inferred from the results of this study. The marked genetic divergence among the three unisexual species suggests that the loss of sex has occurred on at least three occasions within the genus. One of the unisexuals ( $C$. horridus) was genetically distinct from any sexual species, indicating that its sexual ancestor is either extinct or restricted to other geographical regions. By contrast, C. tincta and $C$. fuscatus are genetically very similar, and probably represent a sexual ancestor and its recent unisexual derivative. If so, the different polyploid clones of $C$. fuscatus may owe their origin to matings between diploid $C$. fuscatus females and males of $C$. tincta. The final unisexual, $C$. reticulatus, may hybridize with all of the sexual species, accounting for its extraordinarily high genotypic diversity and its sharing of the alleles present in these taxa. It seems possible that the assembly of such a large number of clones could lead to a run-away process in which sexual species contribute to their own extinction by creating new unisexual derivatives whose competitive superiority is linked to avoidance of the cost of male production. In turn, the loss of its sexual ancestor may doom the unisexual by removing its primary mechanism for generating genotypic diversity. Studies that determine both the ecological and genetic interactions between sister taxa such as $C$. tincta and $C$. fuscatus seem particularly likely to advance understanding concerning the origins of genetic diversity in unisexuals, and the factors leading to the extinction of their sexual ancestors.

\section{Acknowledgements}

This study was funded by a research grant from the Natural Sciences and Engineering Research Council of Canada to P.D.N.H. and a NSERC 1967 Scholarship to J.T. We thank Koen Martens for confirming taxonomic assignments, and Jennie Chaplin for help with sampling and discussions. Terrie Finston, Derek Taylor and two anonymous reviewers provided valuable comments on earlier drafts of the manuscript.

\section{References}

BAUER, H. 1940. Uber die Chromosomen der bisexuellen und der parthenogenetischen Rasse des Ostracoden 
Heterocypris incongruens Ramd. Chromosoma, 1, 620-637.

BELL, G. 1982. The Masterpiece of Nature: the Evolution and Genetics of Sexuality. University of California Press, Berkeley.

CHAPLIN, J. A. 1991. The Effects of Reproduction and Dispersal on the Population Structure of a Freshwater Ostracod. Ph.D. Thesis, University of Wollongong, NSW, Australia.

CHAPlin, J. A. 1992. Variation in the mode of reproduction among individuals of the ostracod Candonocypris novaezelandiae. Heredity, 68, 411-424.

Chaplin, J. A. 1993. The local displacement of a sexually reproducing ostracod by a conspecific parthenogen. Heredity, 71, 259-268.

DAWLEY, R. M. AND BOGART, J. (Eds) 1989. Evolution and Ecology of Asexual Vertebrates. The New York State Museum, Bull. no. 466, Albany, NY.

DELORME, L. D. 1970. Freshwater ostracodes of Canada. Part I. Subfamily Cypridinae. Can. J. Zool., 48, 153-168.

DIETZ, R. 1958. Multiple Geschlechtschromosomen bei den cypriden Ostracoden, ihre Evolution und ihr Teilungsverhalten. Chromosoma, 9, 359-440.

Furtos, N. C. 1933. The Ostracoda of Ohio. Ohio Biol. Surv. Bull., 29, 413-524.

HAVEL, J. E. AND HEBERT, P. D. N. 1989. Apomictic parthenogenesis and genotypic diversity in Cypridopsis vidua (Ostracoda: Cyprididae). Heredity, 62, 383-392.

HAVEL, J. E., HEBERT, P. D. N. AND DELORME, L. D. 1990. Genetics of sexual Ostracoda from a low Arctic site. $J$. Evol. Biol., 3, 65-84.

HEBERT, P. D. N. AND BEATON, M. J. 1993. Methodologies for Allozyme Analysis Using Cellulose Acetate Electrophoresis, 2nd edn. Helena Laboratories, Beaumont, TX.

HEBERT, P. D. N., WARD, R. D. AND WEIDER, L. J. 1988. Clonal-diversity patterns and breeding system variation in Daphnia pulex, an asexual-sexual complex. Evolution, 43, 147-159.

HEBERT, P. D. N., BEATON, M. J., SCHWARTZ, S. S. AND STANTON, D. J. 1989. Polyphyletic origins of asexuality in Daphnia pulex. I. Breeding-system variation and levels of clonal diversity. Evolution, 43, 1004-1015.

HEDGES, S. B., BOGART, J. P. AND MAXSON, L. R. 1992. Ancestry of unisexual salamanders. Nature, 356, $708-710$.

HOFF, C. C. 1942 . The ostracodes of Illinois, their biology and taxonomy. III. Biol. Monogr., 19, 1-196.

LADLE, R. J. 1993. Parasites and sex: catching the red queen. Trends Ecol. Evol., 7, 405-408.

LYNCH, M. 1984. Destabilizing hybridization, general-purpose genotypes and geographic parthenogenesis. Q. Rev. Biol., 59, 257-289.

MAYNARD SMITH, J. 1978. The Evolution of Sex. Cambridge University Press, Cambridge.

MAYNARD SMITH, J. 1986. Contemplating life without sex. Nature, 324, 300-301.
MEISCH, C., WOUlters, K. AND MARTENS, K. 1990. Liste annotée des ostracodes actuels non-marins trouvés en France (Crustacea, Ostracoda). Travaux scientifiques du musée national d'histoire naturelle de Luxembourg. Ministère des affaires culturelles.

MICHOD, R.E. AND LEVIN, B. R. 1988. The Evolution of Sex: an Examination of Current Ideas. Sinauer Associates, Sunderland, MA.

MORITZ, C., MCCALLUM, H., DONNELLAN, S., AND ROBERTS, J. D. 1991. Parasite loads in parthenogenetic and sexual lizards (Heterontia binoei): support for the Red Queen hypothesis. Proc. $R$. Soc. B, 244, 245-250.

PERNIN, P., ATAYA, P. AND CARIOU, M. L. 1992. Genetic structure of natural populations of the free-living amoeba, Nalgeria lovaniensis. Evidence for sexual reproduction. Heredity, 68, 173-181.

ROGERS, J. S. 1972. Measures of genetic similarity and genetic distance. In: Studies in Genetics, VII, pp. 145-153. University of Texas Publication no. 7213.

SuOMALAINEN, E. 1969. Evolution in parthenogenetic Curculionidae. Evol. Biol., 3, 261-296.

SWOFFORD, D. L. AND SELANDER, R. B. 1989. BIOSYS-1. $A$ computer program for the analysis of allelic variation in population genetics and biochemical systematics. Release 1.7. Illinois Natural History Survey, Urbana, IL.

TETART, J. 1969. Technique d'étalement des chromosomes d'invertébrés. Bull. Soc. Zool. Fr., 94, 251-254.

TETART, J. 1978. Les garnitures chromosomiques des Ostracodes d'eau douce. Trav. Lab. Hydrobiol., 69-70, $113-140$.

TRESSLER, w. L. 1959. Ostracoda. In: Edmondson, W. T. (ed.) Fresh-water Biology, pp. 657-734. John Wiley \& Sons, New York.

turgeon, J. 1993. Genetic Diversity in Sexual and Asexual Members of Cyprinotus and Cypricercus (Ostracoda: Crustacea). M. Sc. Thesis, University of Guelph, Canada.

TURGEON, J. AND HEBERT, P. D. N. 1994. Evolutionary interactions between sexual and all-female taxa of Cyprinotus (Ostracoda: Cyprididae). Evolution, 48, 1855-1865.

VANDEL, A. 1928. La parthénogénèse géographique. Contribution à l'étude biologique et cytologique de la parthénogénèse naturelle. Bull. Biol. Fr. Belg., 62, 164-281.

VRIJENHOEK, R. C. 1984. Ecological differentiation among clones: the frozen niche variation model. In: Wohrmann, K. and Loeschcke, V. (eds) Population Biology and Evolution, pp. 217-231. Springer-Verlag, Berlin.

WILKINSON, L. 1990. systat: the System for Statistics. Systat Inc., Evanston, IL.

WILliams, G. c. 1975. Sex and Evolution. Princeton University Press, Princeton, NJ.

ZHANG, L. AND LEFCORT, H. 1992. The effects of ploidy level on the thermal distributions of brine shrimp Artemia parthenogenetica and its ecological implications. Heredity, 66, 445-452. 